\title{
El barrio patrimonial: imaginarios identitarios urbanos y producción de lo público en una ciudad intermedia de la provincia de Buenos Aires
}

Patrimonial Neighborhood: Urban Identitary Imaginaries and
Production of the Public in a Middle-ranged
City of Buenos Aires Province

Ana Cecilia Silva

Universidad Nacional del Centro de la Provincia de Buenos Aires (Unicen) y Consejo Nacional de Investigaciones Científicas y Técnicas (Conicet)

asilva@arte.unicen.edu.ar

\begin{abstract}
$\overline{\text { RESUMEN }}$
Sobre la base de un trabajo etnográfico desarrollado en una ciudad de rango medio del sudeste de la provincia de Buenos Aires, Argentina, este artículo aborda los modos en que se entraman los componentes estructurales del sistema urbano — la ciudad como sistema de sistemas de servicios y consumos colectivos - y los imaginarios identitarios urbanos - la ciudad vivida y significada por sus habitantes - en la producción de lo público en tanto dimensión nodal de la vida urbana. Concretamente, el texto se focaliza en el caso de una asamblea vecinal que impulsa la declaración de un área de protección histórica en el barrio de La Estación, cercano al ferrocarril de la localidad. Se indaga sobre los usos y sentidos de lo público que se ponen en juego en dicho proceso.
\end{abstract}

Palabras clave: barrio, patrimonio, espacio público.

\section{$\overline{\text { ABSTRACT }}$}

This article is based on an ethnographic fieldwork developed in a middle-ranged city of the southeast Buenos Aires Province, in Argentina. It discusses the ways in which structural components of the urban system - the city understood as a system of service systems and collective consumption - and imaginary urban identities - the city lived and symbolized by its inhabitants - are linked in the production of the public, as a main dimension of urban life. specifically, we will refer to the case of a neighborhood assembly that impels the declaration of a protected historic area in the barrio La Estación. We will focus on the uses and meanings of the concept of the public that are involved in this process.

Keywords: neighborhood, patrimony, public space. 
Uno generalmente cree que los recuerdos son de propiedad de uno [...] Pero cuando nos vamos encontrando, vamos haciendo ese entrecruzamiento, y claro, indudablemente la vida era común; los espacios eran comunes, los encuentros [...].

Exvecino del barrio de La Estación (comunicación personal)

\section{Introducción'}

as políticas económicas que se implementaron en distintos países de América Latina durante las últimas décadas del siglo XX implicaron, entre otras situaciones, con sus correspondientes particularidades, una retracción del estado y el desmantelamiento de los servicios públicos (Sader y Gentili 2003). Se trata de un proceso al que el sistema ferroviario no fue ajeno, con distinto grado de impacto en los poblados y urbanizaciones que se habían desarrollado en torno al ferrocarril como elemento dinamizador económico y social (Faccin y Zanini 2013; López y Waddell 2007; Raggio 2012). En Argentina, donde la red ferroviaria había alcanzado la mayor proporción del subcontinente en su época de apogeo, llegando a los $45.000 \mathrm{~km}$ de tendido férreo en la primera mitad del siglo XX, el fin de siglo estuvo marcado por un proceso de desinversión, cierre de ramales y talleres, y privatización del servicio (Martínez 2007). En varias localidades se suspendieron los trenes de pasajeros y numerosos trabajadores y sus familias perdieron sus fuentes de empleo. Grandes predios ferroviarios y sectores urbanos linderos a las estaciones sufrieron un progresivo vaciamiento y abandono, por lo que permanecieron como dolorosos testimonios del deterioro en las condiciones de vida de las mayorías. En ese contexto, fueron surgiendo diversos proyectos de “revitalización” de esas áreas, que recurrieron y recurren a distintas estrategias - especialmente de activación patrimonial (Prats 2005) — para promover la reorientación productiva de las

1 Este artículo se encuadra en un proyecto de investigación en curso que hace parte de la Carrera del Investigador Científico y Tecnológico del Consejo Nacional de Investigaciones Científicas y Técnicas de Argentina (Conicet). El proyecto se titula "Gestión electrónica, imaginarios urbanos y procesos participativos en ciudades de rango intermedio", es dirigido por el Dr. Ariel Gravano y se encuentra radicado en el Núcleo de Producciones e Investigaciones Comunicacionales y Sociales de la Ciudad Intermedia (Proincomsci), en la Facultad de Ciencias Sociales de la Universidad Nacional del Centro de la Provincia de Buenos Aires (Unicen). 
poblaciones afectadas, así como para visibilizar la historia ferroviaria del lugar ${ }^{2}$.

En este artículo nos vamos a referir a un caso reciente de una ciudad de rango medio de la provincia de Buenos Aires (Argentina), donde distintos actores sociales, nucleados en una asamblea vecinal, vienen impulsando la declaración de un "área de protección histórica” 3 en un radio de cuarenta manzanas situadas en las inmediaciones de la estación del ferrocarril, a través de un petitorio presentado en mayo de 2013 ante el Concejo Deliberante del municipio local. El caso nos brinda una puerta de entrada a los modos en que se entraman los componentes estructurales del sistema urbano con los imaginarios identitarios, en particular barriales, en la producción de usos y sentidos de lo público, que en este contexto concreto aparecen en relación con lo que se presenta como de interés público y en contraposición al interés privado, y son parte de la conformación de un colectivo social - la asamblea del barrio de La Estación-para la discusión y visibilización de las demandas ciudadanas.

En torno al proyecto presentado por la asamblea, podemos reconocer dos ejes de confrontación y negociación, con un conjunto de oponentes más o menos abstractos o personificados según el caso. Por un lado, la propuesta de protección patrimonial del barrio de La Estación es presentada explícitamente por los integrantes de la asamblea como una reacción frente a la "especulación inmobiliaria” (diario de campo, comunicación personal) llevada a cabo por los inversionistas privados que, en los últimos años, han comprado y demolido viejas viviendas de empleados ferroviarios y otros edificios del sector para construir en su lugar complejos de departamentos, una práctica que, de acuerdo a los asambleístas, "pone en riesgo la identidad arquitectónica, social y cultural del barrio" ("El barrio de La Estación” 2014) ${ }^{4}$. También se incluye entre estos oponentes a aquellos vecinos propietarios de viviendas que no acompañaron el proyecto por temor a que el establecimiento de un área protegida pudiera implicar limitaciones para disponer de esos bienes.

2 En el contexto latinoamericano, podemos mencionar - a modo de ejemplo y como casos que han sido estudiados también desde una perspectiva socioantropológica- el barrio Peñarol, en Montevideo, Uruguay (Raggio 2012) o la "mancha ferroviaria" de Santa María, en Brasil (Faccin y Zanini 2013).

3 Salvo indicación de lo contrario, las expresiones entrecomilladas corresponden a categorías sociales en uso (Rockwell 1987), tal como han sido relevadas en contextos de registro de campo.

4 Este fragmento hace parte de una entrevista hecha a integrantes de la asamblea, en agosto de 2014. Pese a que algunas de las expresiones son tomadas de apariciones públicas de los asambleístas, como en este caso, hemos optado por preservar su identidad. 
Por otro lado, las distintas actividades organizadas para la difusión del proyecto - charlas, proyección de videos, entrevistas en medios de comunicación, la creación de un blog y de una página de Facebook, entre otras-son mostradas como una forma de "concientización” de los vecinos y de "la comunidad en general” (diario de campo, comunicación personal) sobre el valor histórico y patrimonial del barrio, un área que, tal como se enuncia en el proyecto presentado al Concejo Deliberante, vincula elementos que hacen parte de "la historia de la ciudad como son el trabajo, la cultura, las luchas sindicales y la historia del gremio ferroviario" (asamblea del barrio La Estación, comunicación personal). En este sentido, se interpela al estado en sus distintos niveles y específicamente en su rol regulador. En el nivel provincial, se plantea la inexistencia de la figura de área de protección histórica (APH), que sí se aplica en algunas ciudades del país, como en la ciudad autónoma de Buenos Aires o en Rosario ${ }^{5}$. Si bien hay una tendencia al reconocimiento de “conjuntos” patrimoniales, específicamente en el caso de los sistemas arquitectónicos ferroviarios bonaerenses (Tartarini 2007), las figuras jurídicas disponibles solo permiten la protección de bienes patrimoniales aislados. En el nivel municipal, los integrantes de la asamblea demandan la protección de un interés colectivo superior al de los propietarios individuales, así como el fortalecimiento de los controles y regulaciones sobre las nuevas construcciones que se realizan en el barrio. En este caso, la interpelación se plantea de manera más directa hacia ciertas áreas del municipio o hacia ciertos funcionarios en particular, como en el caso de la Dirección de Obras Públicas y la Dirección de Desarrollo Urbano, así como de sus responsables.

Es interesante destacar que, en algunas de las respuestas de actores del municipio, aparece la apelación a ciertos instrumentos de planificación urbana, como el Plan de Desarrollo Territorial (PDT) ${ }^{6}$, según el cual la zona de la estación reúne una serie de indicadores - por ejemplo, la provisión de servicios urbanos básicosque la tornarían apta para densificar la población y dar solución a una parte de la demanda habitacional de la ciudad. En este sentido, los actores estatales apelan también a una idea de bien común que, desde el punto de vista de los integrantes de la asamblea, favorecería en realidad a intereses particulares: los de los inversionistas privados y la “especulación inmobiliaria”. Nos preguntamos entonces, de

5 En el siguiente enlace de la página web de la municipalidad de Rosario se explica brevemente en qué consiste la figura y se mencionan las distintas áreas de la ciudad que han sido declaradas APH. http://www.rosario.gov.ar/sitio/arquitectura/patrimonio/aph.jsp. tectos y asesores especialistas, destinado a brindar un diagnóstico y unas líneas directrices para el crecimiento urbano de la ciudad en los próximos años. 
cara a estas apelaciones al interés público o bien común que resultan contradictorias entre sí, ¿cuáles son los contenidos concretos que se les asignan a estas categorías en contextos también concretos? ¿De qué modos se construyen, se negocian o se imponen esos contenidos?

En otra dimensión de análisis, que se entrama con las anteriores, el proyecto de la asamblea involucra la construcción de una memoria colectiva (Halbwachs 2004; Portelli 1989) sobre las particularidades localizadas que asumió la presencia del sistema ferroviario en la ciudad y del conjunto de actores sociales vinculados a este. Las configuraciones y reconversiones de los perfiles productivos y formas espaciales urbanas implican tanto procesos estructurales como experiencias subjetivas, incluyendo los modos de interpretar y dotar de sentido a esas experiencias. En esa construcción, en el caso estudiado observamos que el pasado común cobra especial relevancia en la significación del presente y en la proyección a futuro del barrio y de la ciudad. ¿Qué características adquiere, entonces, la producción de lo público en el conflicto por la concreción de esa ciudad anhelada?

\section{Algunas breves consideraciones teórico-metodológicas}

El artículo recupera algunos ejes de estudio sobre ciudades medias de la provincia realizados dentro del Núcleo de Producciones e Investigaciones Comunicacionales y Sociales de la Ciudad Intermedia (Proincomsci). Este último es un colectivo de investigación dirigido por los profesores Ariel Gravano y Patricia Pérez, de la Facultad de Ciencias Sociales de la Unicen. El enfoque de nuestro trabajo se sitúa en una antropología de lo urbano (Gravano 2013), que busca tomar distancias respecto a las aproximaciones "ghettizantes” de una antropología en la ciudad", y en la que el contexto urbano cumple la función de marco o escenario para, en cambio, poner en cuestión la constitución histórico-estructural de lo urbano, en su dialéctica con la producción simbólica de la vida urbana (Gravano 2005).

En este sentido, se propone estudiar lo urbano tal como se describe a continuación:

\footnotetext{
7 Ver en particular los capítulos "Lo urbano como objeto antropológico" y "La imaginación antropológica", de Ariel Gravano, y el artículo de Carlos Herrán "La ciudad como objeto antropológico", en Antropología de lo urbano (Gravano 2013).
} 
[E]n términos estructurales - entendido como el sistema de servicios de uso común, colectivo y público distribuido en el espacio concentrado- [y en necesaria articulación con] los sistemas de representaciones discursivas, icónicas, simbólicas e identitarias que componen los imaginarios de estos sistemas de servicios de parte de los distintos actores sociales que se ven involucrados en su producción y su uso desigual. Se ponderará la continuidad en el abordaje de una dimensión de análisis en la cual toma importancia no solamente cómo se vive en las ciudades sino cómo se viven las ciudades. Y asimismo se articula con los modos de gestión de estos servicios, dentro de los cuales [nos] focalizaremos en los procesos institucionales que asocian instancias de planificación con invocada participación ciudadana. (Proincomsci 2013)

La metodología es etnográfica, con énfasis en la búsqueda de comprensión de los significados de los actores y su vinculación con los procesos histórico-estructurales que los trascienden (Achilli 2005). El diseño metodológico, entendido como un proceso reflexivo que opera en todas las etapas de la investigación (Hammersley y Atkinson 1983, 42), está enfocado desde una perspectiva relacional y situada de los procesos sociales, con la finalidad de reconstruir el contexto de la ciudad en su trayectoria histórica y en su configuración actual.

Nos centramos en las ciudades de rango medio ${ }^{8}$, basándonos en la relativa vacancia de estudios antropológicos de esta escala, lo cual contrasta con la cantidad de tales espacios en la realidad urbana argentina (es decir, la mayoría de las ciudades del país son “medias”). Se suele preconcebir lo urbano de acuerdo con modelos de dimensión metropolitana, tanto a nivel teórico como de sentido común, y sobre todo desde la perspectiva preponderante de la gestión político-institucional (Silva y Gravano 2013).

Definimos, entonces, el sistema urbano como

[...] el conjunto de aparatos y dispositivos institucionales para la provisión pública de consumos colectivos, en su dimensión espacial y su consecuente valoración material y simbólica. [...] un sistema de sistemas satisfactores de servicios ciudadanos de infraestructura, equipamien-

8 La categoría de ciudad media o intermedia suele construirse a partir de indicadores estructurales y de funcionalidad, en un rango poblacional amplio que abarca desde los 50.000 a los 500.000 habitantes. Desde la perspectiva teórica y metodológica que suscribimos, es necesario situar previamente el contexto e incluir los aspectos significacionales del espacio urbano. En ese sentido, una de las constantes en las investigaciones de nuestro equipo ha sido el intento de aportar a la consideración y comprensión de las dinámicas simbólicas que constituyen los entramados sociohistóricos específicos, en las ciudades medias bonaerenses (especialmente desarrollado en Boggi y Galván [2008]; Gravano [2005]). 
tos, vivienda, comunicación, regulación espacial, educativos, judiciales, de salud, empleo, mediáticos, etc. (Silva y Gravano 2013, 2)

El sistema urbano es producto de transformaciones y luchas permanentes que se dan tanto a nivel estructural como en una dimensión conformada por imaginarios sociales urbanos, entendidos como un conjunto de representaciones histórica y culturalmente construidas que tienen como referente el espacio urbano (García Canclini 2005; Gravano 2005; Ar. Silva 1992) ${ }^{9}$. Lo urbano puede, así, ser aprehendido como proceso dinámico, de tensión entre su permanente reforma y la voluntad de preservación, como un proceso de duración (Carvalho da Rocha y Eckert 2013).

A partir de la interrogación acerca del proceso histórico de conformación de identidades colectivas e imágenes vigorosas (Lynch 1966) que parecen, en los sucesivos contextos, resultar eficaces en la enunciación de la ciudad como una pretendida totalidad ante propios y extraños, sostenemos que las identidades urbanas se constituyen en un desarrollo que se despliega diacrónicamente, en el que se reactualizan selectivamente elementos del pasado que resultan significativos en el presente (Williams 1980). Es así como se construyen las distintas capas del palimpsesto urbano $^{10}$ (Gravano 2005). La metáfora del palimpsesto nos permite advertir la textura de las identidades urbanas, en la medida en que las sucesivas imágenes van dejando sus huellas, entre y a partir de las cuales se inscriben las "nuevas" en cada contexto histórico y social específico. Siguiendo esta hipótesis, las diversas imágenes de la ciudad se superponen en el imaginario, lo que da lugar a una estratificación cuyos ejes de anclaje difieren de una ciudad a otra, de acuerdo con el proceso histórico específico de cada localidad, en su dialéctica con la construcción de la identidad urbana.

Como podemos ver en el caso del barrio de La Estación, estos usos del pasado se invocan en relación con los proyectos planeados a futuro para la ciudad, en la negociación y la conflictividad en torno a distintas problemáticas urbanas, a los modos de gestionarlas y “resolverlas”. En estos debates se activan, entre otras, las cuestiones sobre las acciones y valores en procesos de adscripción identitaria

9 Esta concepción de los imaginarios urbanos es deudora de una comprensión más general de los imaginarios sociales que busca anular la dicotomía esencialista entre lo real y lo imaginario, para desplazar sus fronteras recíprocas al espacio semántico de la realidad (Ansart 1989; Castoriadis [1989] 2003; Colombo 1989).

10 “[...] así como cuando al escribir un manuscrito se debía apelar a la superficie rugosa y texturada de un papiro del que se habían borrado las señas evidentes de una escritura anterior, pero que aún conservaba las huellas de los trazos ausentes, la ciudad ha ido entramando imágenes de sí misma que siguen dejando huella y sirven de superficie rugosa para la reescritura de imágenes ulteriores" (Gravano 2005, 35). 
acerca de quiénes son más "merecedores” de la ciudad, una moneda de cambio simbólico que mediatiza su valor de uso en tanto sistema de sistemas de servicios y consumos colectivos (Ar. Silva 2013).

Dado que, como veremos, las interacciones mediadas por las tecnologías digitales asumen este lugar significativo en las prácticas de la asamblea, buscamos incorporar las nuevas perspectivas sobre los medios digitales y electrónicos como contextos para la llamada ciberetnografía (Boggi 2009). Se trata de procesos que no siempre pueden ser observados de manera presencial y directa, ya que se fundan en modos de interacción multisituados, cuyo alcance solo puede ser abordado de manera limitada y fragmentaria. Pero, pese a su aparente virtualidad, como ha señalado Estela Grassi (2004), no hay que perder de vista que se trata de dimensiones bien concretas de la vida social, en las que circulan, se producen, reproducen y cuestionan las categorías que clasifican a los grupos sociales, así como los recursos de percepción e interpretación de la realidad social.

En estas páginas, entonces, recuperamos la articulación entre la gestión urbana, lo estructural y los imaginarios identitarios, a partir de la focalización territorial que realizamos en un barrio de una ciudad media de la provincia de Buenos Aires.

\section{“Nos merecemos un lugar histórico"}

Ubicada hacia el sudeste de la provincia de Buenos Aires, la localidad posee una población de alrededor de 120.000 habitantes (Indec 2010). Las características de su suelo y su paisaje permitieron el desarrollo de dos importantes actividades económicas en el partido (además de la agroganadería y la industria, principalmente metalmecánica): la explotación de canteras de piedra —en especial de granito-y el turismo, a las que se sumaron, con mayor notoriedad en los últimos años, emprendimientos inmobiliarios en la zona serrana, destinados, por un lado, a la provisión de servicios turísticos (cabañas y hoteles) y, por otro, a la vivienda de sectores de altos ingresos (Migueltorena y Lan 2013).

Las transformaciones operadas por las construcciones en las sierras y otros sectores de la ciudad han sido objeto de conflictos más o menos visibilizados en el espacio público local, entre distintos intereses y racionalidades, respecto a la apropiación y ocupación del suelo. El paisaje serrano constituye un elemento con fuerte valor identitario para la población local (Ar. Silva 2011), lo cual contribuyó a que en las últimas décadas el modelo de explotación intensiva 
de las canteras fuera ganando una creciente oposición y se conformaran organizaciones ambientalistas que trabajan en pos de la preservación de las sierras y del cese de las voladuras. Este conflicto condujo finalmente a la sanción de la Ley Provincial de Paisaje Protegido n. ${ }^{0}$ 14126, en $2010^{11}$. Aunque en la actualidad persisten tensiones en torno a la efectiva implementación de esta ley y de otros instrumentos jurídicos asociados a ella (como el Plan de Manejo Ambiental), se trata de un antecedente reciente de protección del patrimonio (natural) local que ha sido invocado en distintas oportunidades por integrantes de la asamblea del barrio de La Estación, con una ambivalencia que vale la pena destacar. Por un lado, se subraya que "hay una preocupación de la comunidad local por proteger y preservar cuestiones que tienen que ver con lo propio, que hacen a la identidad [...]" (integrante de la asamblea, comunicación personal) ${ }^{12}$; pero, por otro lado, se señala que "lo de las sierras [los] afectaba a todos; esto es más de un sector de la ciudad” y, por lo tanto, "hay que parlarlo ${ }^{13}$ más, hay que convencer" (integrante de la asamblea, comunicación personal) ${ }^{14}$.

La asamblea del barrio de La Estación comenzó a conformarse hacia fines de 2012, a partir de la iniciativa de un grupo de vecinos y vecinas que manifestaron su preocupación por el "deterioro" del barrio y la "pérdida” de su fisonomía característica a manos de la "especulación inmobiliaria”, y resolvieron "hacer algo para detenerlo" (integrante del grupo fundador de la asamblea, comunicación personal). Inicialmente, sus integrantes utilizaban de manera indistinta los términos asamblea y comisión, hasta que en una de las reuniones resolvieron adoptar el primero, ya que consideraron que correspondía mejor a los propósitos de "horizontalidad" del grupo — "es más democrático... la comisión implica una jerarquía, hay que armar una comisión directiva...”- ${ }^{15}$ (integrante de la asamblea, comunicación personal).

Quienes participan con regularidad de las actividades de la asamblea son alrededor de 20 hombres y mujeres de edades aproximadas entre los 25 y los 95

11 El conflicto fue estudiado en profundidad por Agustina Girado (2012), investigadora también integrante del Proincomsci. Esta declaración surgió en el marco de una reunión ordinaria en la que se estaba discutiendo cómo ampliar el alcance del reclamo más allá del contexto barrial. sentido de argumentar, de hablar para convencer a otro de algo. nes similares en distintas situaciones. presentes asentían con la cabeza. Ninguno manifestó preferir la denominación de comisión y la discusión se dio por saldada por unanimidad. 
años, con trayectorias sociales ${ }^{16}$ diversas, a partir de las cuales $-\mathrm{y}$ a la luz de los registros de campo- es posible distinguir dos subgrupos. Por un lado, un grupo conformado por algunos trabajadores ferroviarios jubilados, dentro del que también se establece una distinción significativa: se trata de "ferroviarios de los de antes, los de ahora no lo sienten, salvo casos muy contados, trabajan de ferroviarios pero no son ferroviarios" (integrante del grupo fundador de la asamblea, comunicación personal). De ese grupo también hacían parte familiares de ferroviarios (hijos, esposas y viudas). Por otro lado, un grupo conformado por profesionales e intelectuales: un profesor de historia especializado en historia ferroviaria, algunos arquitectos - uno de ellos con un posgrado en patrimonio-, un abogado, un periodista, un escritor, una licenciada en turismo y varios docentes de escuelas medias. A ellos se fueron sumando otros actores del entramado social barrial, referentes ${ }^{17}$ de instituciones, comerciantes y otros vecinos. La mayoría viven o trabajan actualmente en el barrio, o vivieron allí durante un tiempo, e incluso hay quienes residieron en él, en la misma casa, prácticamente toda su vida ${ }^{18}$.

Los profesionales detentan la posición de portavoces de la asamblea. Convocan y conducen las reuniones, salen a hablar con los medios de comunicación o en las distintas presentaciones públicas del proyecto. Contrasta, en no pocas oportunidades, la voluntad manifiesta de lograr una "horizontalidad" en la gestión del colectivo con la jerarquización de hecho que opera en la toma de algunas decisiones e, incluso, en el uso de la palabra. A los ferroviarios y sus familiares, la mayoría de edades avanzadas, se les suele asignar el lugar de depositarios de la memoria del barrio, de "historia viva" de este. Esto se debe a que son poseedores de saberes ligados a la experiencia que de otro modo aparecerían como devaluados en relación con aquellos legitimados por las instancias de consagración simbólica, especialmente la institución universitaria: "Bueno, no sé si lo que te dijimos te sirve de mucho, por ahí no tiene importancia, no sé... Ahí el que sabe es H. [profesor de historia 'especialista' en historia ferroviaria y miembro del [...] sistema de rasgos pertinentes de una biografía individual o de una clase de biografías" (Bourdieu 2003, 31).

En Argentina es habitual usar la palabra referente para hablar de una persona o de un grupo de personas que representan o hacen las veces de portavoces de una institución o agrupación, así no hayan sido designados oficialmente como tales. blea. Ella tiene alrededor de 80 años, es hija de ferroviario y vive en la misma casa desde que tenía un año de edad. Él tiene 85 años, es ferroviario jubilado y reside en el barrio desde su nacimiento, en la década del treinta. 
'grupo fundador' de la asamblea]", expresaba en una entrevista una vecina "de toda la vida” del barrio, hija de un maquinista.

Dentro del grupo de los profesionales, varios - en especial las mujeresposeen trayectorias de militancia y participación en distintas organizaciones ciudadanas: por ejemplo, una de ellas es una conocida activista feminista en el medio local y otra, de más edad, participó además en una de las organizaciones ambientalistas a las que hacíamos referencia más arriba. Puede reconocerse entonces el despliegue de un saber hacer político que resulta relevante al momento de considerar los repertorios de acción colectiva ${ }^{19}$ (Auyero 2002) puestos en juego o evitados ${ }^{20}$.

La asamblea tuvo su primera aparición pública el 9 de mayo de 2013, cuando presentó ante el Concejo Deliberante local el proyecto titulado "El barrio de La Estación como área de protección histórica”21. El petitorio, avalado por unas 2.500 firmas y adhesiones institucionales, contiene varios puntos, referidos a la necesidad de establecer medidas de protección edilicia a las edificaciones contenidas en el área de protección histórica, la implementación de regulaciones sobre nuevas construcciones, la creación de un paseo temático ferroviario en las instalaciones de la estación y en la plaza que se encuentra enfrente, así como el cambio de denominación de un tramo de la avenida de La Estación, entre otros.

Poco tiempo después de esa presentación hicimos contacto con uno de los referentes del "grupo fundador", a partir de la propuesta de un proyecto de extensión universitaria para trabajar en conjunto con organizaciones sociales y comunitarias localizadas en el barrio, en el desarrollo de actividades "artístico-

19 Javier Auyero recupera el concepto de repertorio de acción colectiva del historiador Charles Tilly (2000), "el cual refiere a 'un conjunto limitado de rutinas que son aprendidas, compartidas y ejercitadas mediante un proceso de selección relativamente deliberado' y nos invita a examinar las regularidades en las maneras de actuar colectivamente en defensa o prosecución de intereses compartidos, a lo largo del tiempo y del espacio" (Auyero 2002, 188).

Como veremos, hasta el momento la asamblea no ha recurrido a manifestaciones en el espacio público urbano, como marchas, sentadas o cortes de calles, que suelen ser modos frecuentes de protesta. Ha optado por darles visibilidad a sus reclamos en los medios de comunicación y redes sociales en Internet, por la negociación directa con diferentes agentes estatales a partir del pedido de reuniones y audiencias, y por la realización de distintas actividades de difusión y concientización, como charlas y mesas de debate, entre otras prácticas.

21 Para la presentación, la asamblea hizo uso de la Banca 21, una figura que permite que ciudadanos, ciudadanas u organizaciones ciudadanas puedan presentar un proyecto de una manera formal equivalente a "como si lo presentara un legislador" (Honorable Concejo Deliberante de Tandil s. f.). El proyecto debe ser entregado con anterioridad al Concejo Deliberante, junto con un formulario de solicitud que puede descargarse de la página web. La presentación debe atenerse a un reglamento que, entre otras cuestiones, establece un tiempo máximo de diez minutos para la exposición del proyecto. 
Figura 1. Localización del barrio dentro de la planta urbana

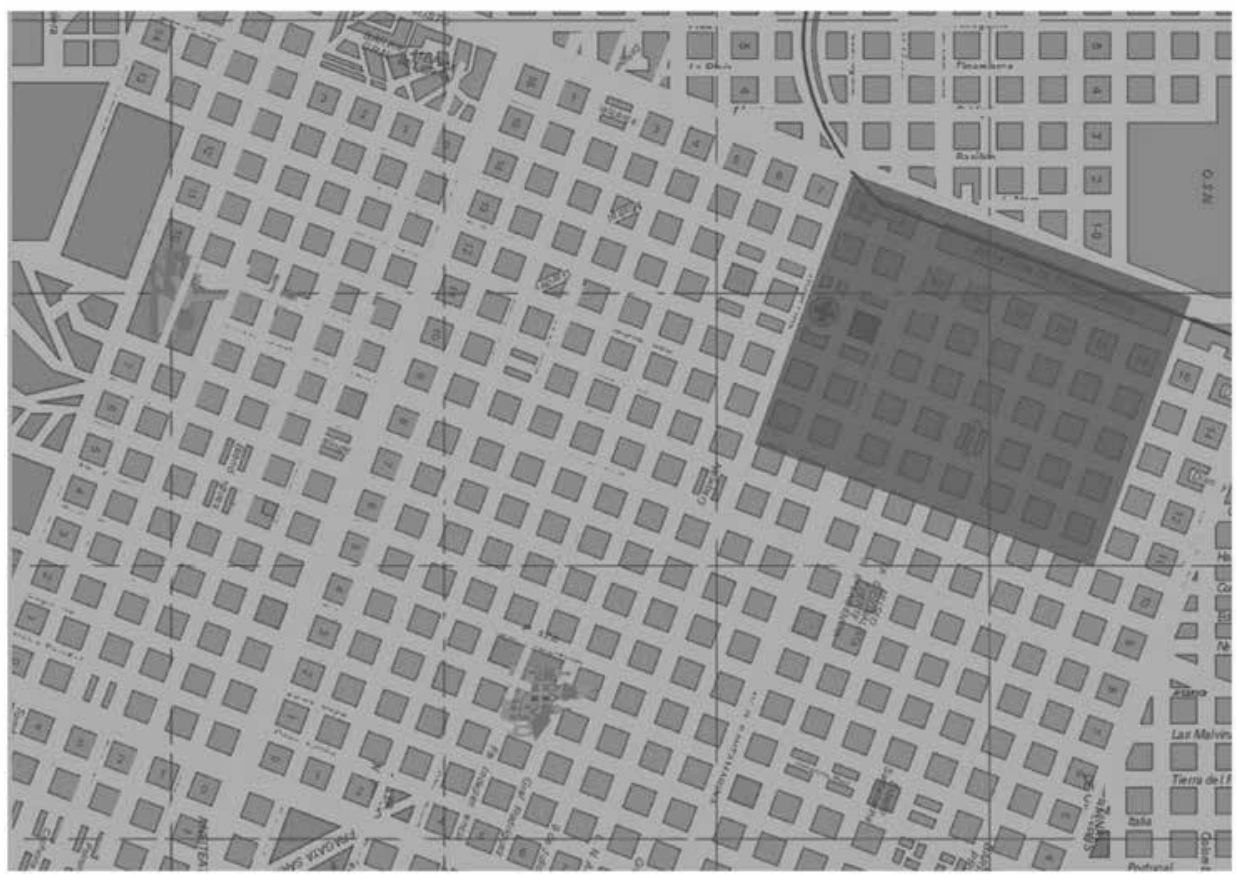

Fuente: Elaboración propia.

culturales" (estuvieron involucradas en el proyecto la Facultad de Arte y la Facultad de Ciencias Humanas). Desde entonces comenzamos a participar de manera regular en las reuniones de la asamblea y, poco tiempo después, surgieron ciertos interrogantes que interpelaban fuertemente los recorridos de investigación que veníamos realizando en el contexto de ciudades medias y que reseñamos más arriba.

El barrio de La Estación es presentado por los integrantes de la asamblea como "el primer barrio de la ciudad" - es decir, el primer sector con características de barrio-, lo cual constituye un argumento central a la hora de fundamentar el pedido de protección patrimonial, como veremos enseguida. Es importante señalar que la noción de barrio aparece como una referenciación indispensable en la articulación del proyecto y en la formulación de peticiones de acción a los agentes estatales hechas por los integrantes de la asamblea. En el presente trabajo, ponemos dicho concepto en diálogo con una conceptualización de lo barrial que trasciende la idea de escenario o recorte espacial, para ser objeto de significación y constituir de ese modo un conjunto de valores plasmados históricamente en la totalidad urbana (Gravano 2011). 
Se establecen comparaciones con "el primer barrio" de la ciudad de Buenos Aires:

A este barrio hay que preservarlo, y muchos somos los que creemos esto. Fue el primer barrio de la ciudad [...]. Así como Buenos Aires tiene a San Telmo, un lugar muy pintoresco, nosotros nos merecemos un lugar histórico. No digo [una] pequeña San Telmo [...], sino el barrio de La Estación, con mayúscula y todas las letras. (Integrante de la asamblea, comunicación personal)

El barrio de La Estación comenzó a conformarse a partir de la llegada de un ramal del Ferrocarril Sud a la localidad en 1883. El ferrocarril fue un elemento muy relevante en la consolidación del modelo agroexportador que caracterizó a la economía argentina de finales del siglo XIX (Rapoport 2006), así como en el proceso de urbanización y modernización del territorio bonaerense. El impacto que tuvo en la transformación de la vida lugareña ha llevado a hablar de una “segunda fundación” de la ciudad (Nario 1996).

En los alrededores de la estación fueron construyéndose distintos edificios vinculados a la provisión de servicios para el ferrocarril, así como viviendas para los trabajadores ferroviarios. Posteriormente, con el auge de la actividad gremial a principios del siglo XX, se construyeron instalaciones como las del Club y Biblioteca Ferrocarril Sud (1919), el Salón de la Confraternidad Ferroviaria (1928) o, más tarde, el Policlínico Ferroviario (1953). Esas construcciones han corrido una suerte desigual. El Salón de la Confraternidad, por ejemplo, fue construido en la década del veinte para albergar a los dos gremios ferroviarios (Unión Ferroviaria y La Fraternidad). Funcionó intensamente durante la primera mitad del siglo como espacio de actividades sindicales, políticas - fundamentalmente ligadas a la adscripción de muchos de los trabajadores ferroviarios al socialismo, que celebraban en el local fechas como el $10^{\circ}$ de mayo, en conjunto con el Partido Socialista (Barandiarán y Silva 2014) — y también como un espacio para la realización de bailes, kermeses y la presentación de espectáculos —obras teatrales, proyecciones cinematográficas, actuación de orquestas- La actividad allí fue atravesando sucesivos momentos de minoración y reactivación hasta que, en la década del ochenta, el lugar fue definitivamente abandonado por los gremios y se cerró. En 2003, se formó la Asociación de Amigos del Teatro de la Confraternidad y, en 2007, se logró la reapertura del edificio como sala teatral. En cambio, el Policlínico Ferroviario dejó de funcionar a fines de la década del noventa y desde entonces permanece en estado de abandono. Estos edificios constituyen 
Figura 2. Viviendas del barrio de La Estación en 2014

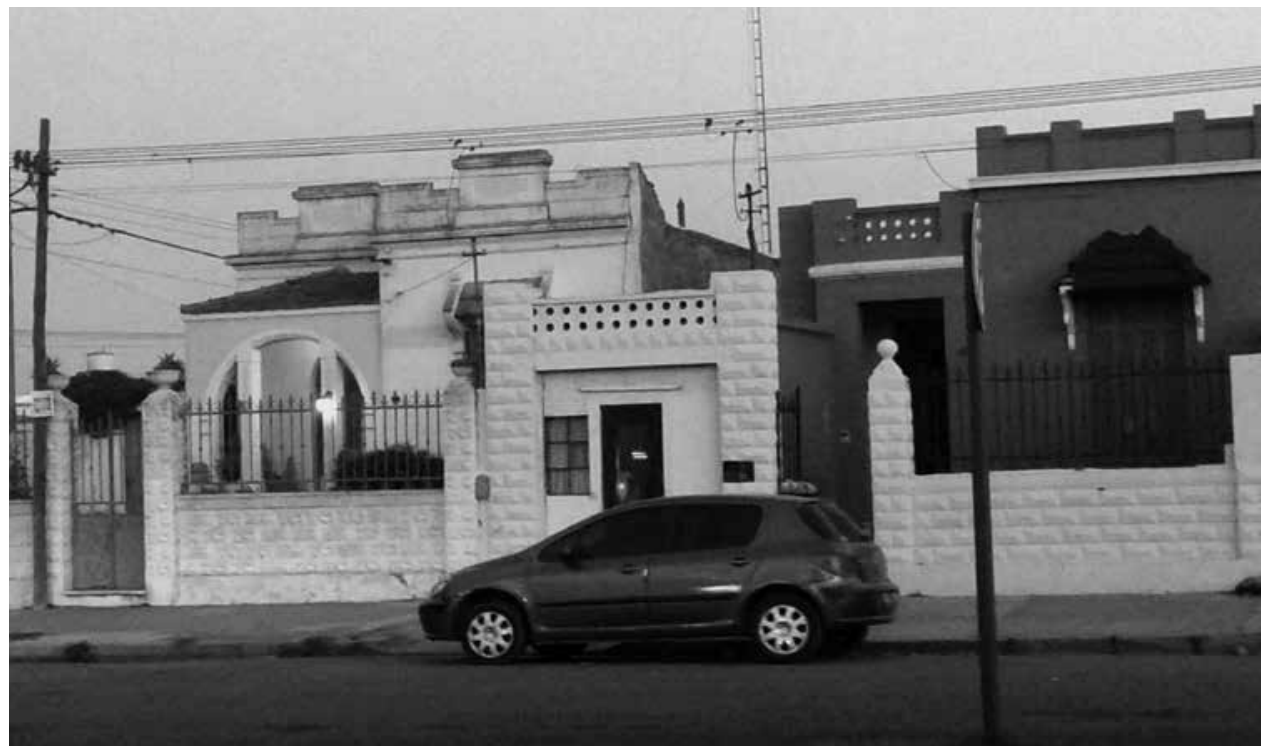

Fuente: Fotografía de la autora.

referentes centrales de la identidad barrial (Barandiarán y Silva 2014), así como de las reivindicaciones de la asamblea.

La actividad económica floreciente de la región durante toda la primera mitad del siglo XX implicó la expansión tanto de las fuerzas productivas como de las fuerzas reproductivas del espacio y sus funciones comunicativas. Esa etapa alcanzaría su punto más alto en la década del cincuenta, para entrar luego en un proceso regresivo en el último tercio del siglo, marcado por la crisis de la actividad industrial y la retracción del papel de Argentina en la provisión de manufacturas en el mercado mundial. La reestructuración capitalista del territorio argentino a partir de la última dictadura militar (1976-1983), consolidada con las reformas neoliberales de la década del noventa, terminó con la disolución de la empresa estatal (Ferrocarriles Argentinos) y el desmantelamiento de buena parte de la gigantesca red ferroviaria nacional. En la estación local, muchas de las instalaciones cayeron en desuso o comenzaron a deteriorarse por falta de mantenimiento. En algunos casos se reconvirtió su finalidad original, para dar lugar a organizaciones comunitarias que desarrollan allí sus actividades ${ }^{22}$. En 2006, se suspendió

22 En las instalaciones de la estación funcionan actualmente la Escuela Municipal de Música Popular, la Escuela Municipal de Teatro, el Taller de Picapedreros y la Incubadora de Arte, por mencionar solo algunas. 
el servicio de pasajeros desde y hacia la localidad, el cual se reactivaría solo seis años más tarde, el 28 de junio de 2012. Actualmente cuenta con una frecuencia de dos días a la semana con destino a la estación Constitución, de la ciudad de Buenos Aires, aunque con grandes falencias de infraestructura que persisten.

El proyecto de la asamblea señala, además, que la estación fue "durante varias décadas, uno de los lugares preferidos para las familias [...] como atractivo paseo de los fines de semana", y se solicita "reactivar la entrada (calle interna) de la estación, a partir del montaje de un paseo temático ferroviario en el que se contemple la influencia y la pujanza que generó el ferrocarril en nuestra ciudad, la región y en el barrio [...]" ("Entrevista a integrante de la asamblea” 2012), junto a una serie de acciones para el reconocimiento simbólico de "trabajadores ferroviarios y otros vecinos que tuvieron una actuación destacada en el campo profesional, en el cultural, en el social y el sindical" (integrante de la asamblea, comunicación personal). Un ejemplo de esto último es la imposición del nombre de un mutualista ferroviario de las décadas del cuarenta y el cincuenta a una calle del paseo temático, de activa participación sindical en el contexto de la nacionalización de los ferrocarriles por el gobierno peronista. También está el caso de una escultura erigida en homenaje a una militante del Partido Comunista que "rompió los moldes políticos masculinos de su época", o el del cambio de denominación de un tramo de la actual avenida Coronel Benito Machado por avenida de los Trabajadores Ferroviarios.

En relación con esa última propuesta, consideramos significativo resaltar cómo se van construyendo, a partir de la argumentación, distintos oponentes -más o menos concretos y personalizados según el caso- frente a los cuales es posible establecer las propias tomas de posición con respecto a los actores seleccionados, para así integrar el repertorio patrimonial que se reivindica. Dichos actores encarnan además un conjunto de valores que se busca asociar positivamente con el ethos barrial (Gravano 2013):

Personaje polémico [...] al coronel Benito Machado hasta lo han llegado a definir como la versión local de Julio Argentino Roca [...] Machado es un hombre aceptado por una generación de conservadores de nuestra ciudad. [...] Si bien en algún momento [para el cambio de denominación] se deslizó algún nombre propio de algún trabajador de los años cuarenta o cincuenta, dejábamos afuera a muchísimos protagonistas notorios que tenían que ver con los obreros del riel. Avenida de los Trabajadores Ferroviarios involucra toda la historia, desde el primer empleado de 1883 hasta los administrativos de hoy. (Integrante de la asamblea, comunicación personal) 
El tramo a modificar sería de diez cuadras, en una primera instancia, porque los integrantes de la asamblea confían en que "las futuras generaciones cambiarán el nombre a la calle [en el tramo restante], para la reivindicación de otras figuras y luchas” (integrante de la asamblea, comunicación personal).

Esta selectividad de los referentes que componen el repertorio patrimonial, según hemos podido observar, se configura en un proceso sumamente dinámico, dado que se produce de modo relacional, en el contexto de los referentes reivindicados por otros actores que también buscan visibilidad en el espacio urbano. En noviembre de 2014, la asamblea publicó un comunicado en su página de Facebook, que envió también a los medios de comunicación locales, a raíz de las declaraciones de algunos miembros del Partido Justicialista sobre el reemplazo de un busto del general Juan Domingo Perón, que actualmente se encuentra en la plaza frente a la Estación de Ferrocarril, por un monumento de mayores dimensiones. La asamblea repudió enérgicamente esa iniciativa, indicando que el proyecto de un paseo temático ferroviario había sido presentado en primer lugar y que la inclusión de un monumento a gran escala no resultaba "compatible” con ese proyecto. En la reunión previa a la emisión del comunicado, una de las integrantes de la asamblea decía con tono irónico: "Bueno... estamos diciendo que vamos a mantener el busto que está, no que lo vamos a tapar con una planta que es lo que a mí me gustaría hacer... [risas]” (integrante de la asamblea, comunicación personal).

La referencia a las tensiones suscitadas en torno a la figura de Perón no es menor, ya que remite a fuertes conflictos políticos en la historia de los gremios ferroviarios que enfrentaron a sectores peronistas con socialistas y comunistas (Mengascini 2011). Resulta significativo que en el discurso de la asamblea se destaquen aquellos elementos que hacen referencia a lo ferroviario o lo barrial como componentes homogeneizadores de la memoria colectiva, lo que soslaya las interpelaciones a las trayectorias y adscripciones político-partidarias de sus integrantes -en particular aquellas que tienen mayores resonancias en la actualidad ${ }^{23}$ - que podrían operar como ejes de fragmentación en la identidad barrial $^{24}$.

El petitorio contempla, asimismo, la modificación del código de edificación municipal, estableciendo características especiales para las futuras construcciones que se realicen dentro del área de protección histórica, como alturas

23 En los últimos años, el sector ferroviario ha sido un foco recurrente de conflictos para el gobierno, y ha alcanzando su punto de mayor notoriedad en el caso del accidente en la estación de trenes de Once, de la ciudad de Buenos Aires, en febrero de 2012. 
máximas y retiros escalonados respecto de la línea municipal, entre otras. Este es señalado por integrantes de la asamblea como uno de los puntos más "difíciles” del proyecto para su aprobación (“nos estamos metiendo con el código de edificación”). Asimismo, constituye uno de los aspectos en los que se recurre a la sustitución del valor de cambio de la "especulación inmobiliaria”, tal como se la percibe actualmente ("indiscriminada”, "sin criterio”, "sin identidad”), por el de otros atractivos: "el valor se logra a través de ser un lugar único. Una zona residencial, de casas bajas; hay otros valores” (integrantes de la asamblea, comunicación personal).

Desde el ingreso del proyecto al Concejo Deliberante, los integrantes de la asamblea vienen siguiendo el recorrido del expediente en las distintas instancias legislativas y ejecutivas municipales, apelando a sus "contactos” con los distintos bloques políticos para "ir empujando" su avance, al tiempo que intentan no quedar "pegados” a ningún partido en particular. Han solicitado audiencias con concejales y mantuvieron una reunión con el intendente, en la que obtuvieron como respuesta que se realizaría un estudio para analizar la viabilidad de la implementación de un área de protección histórica. En este punto adquiere relevancia la percepción diferencial del tiempo de los distintos actores: por parte de los asambleístas, hay una manifestación de “urgencia” que se expresa en el siguiente diálogo entre dos integrantes de la asamblea en el contexto de una reunión ordinaria:

- [...] ya va a hacer un año que se presentó el proyecto.

- Con todo lo que implica un año en términos del deterioro del barrio.

-Sí, por eso pensamos de entrada en un plan quinquenal; ya pasó uno.

En cinco años destruyeron el barrio.

Por otra parte, desde la perspectiva del ejecutivo municipal, es necesario dedicar un tiempo "razonable” a la realización de un diagnóstico para que se hagan las cosas "con seriedad", ya que se considera que hay que tener en cuenta "los intereses de todos los vecinos” (reunión entre asambleístas e intendente, comunicación personal).

Como parte de sus estrategias para dar difusión y posicionar sus reclamos, así como para presionar al poder político, los integrantes de la asamblea han recurrido en reiteradas oportunidades a distintos medios de comunicación locales y a la creación de un perfil y una fan page en la red social Facebook ${ }^{25}$. En la

25 Los perfiles permiten tener hasta 5.000 "amigos", que pueden ver y compartir los contenidos publicados y, de acuerdo con la configuración de privacidad, hacer comentarios sobre esos contenidos, publicar otros y demás. Por su parte, las fan page están destinadas a 
medida en que ese espacio ha permitido una gestión relativamente autónoma de la visibilidad, se ha constituido en uno de los medios privilegiados de difusión del proyecto y de las actividades de la asamblea. Esto contrasta con lo que ocurre en el contexto de los medios “tradicionales”, en los que el contenido de la noticia, los tiempos y modos de presentarla deben ser negociados con los actores sociales que allí intervienen: periodistas, locutores y locutoras, camarógrafos y camarógrafas, entre otros.

En las reuniones se dedica un tiempo considerable a discutir y evaluar las estrategias de posicionamiento en los medios:

Tuvimos una reunión con concejales, con todos los bloques... Lo cierto es que a todos les interesa pero el proyecto duerme en un cajón. [...] Y, si no le pueden sacar rédito político [...] Pero ¿por qué se opondrían? [...] Por negligencia, es largo, se tienen que poner a estudiar [...] Acá hay que salir a los medios [...] Tenés que salir para decir que el expediente duerme en un cajón... Si no salís a molestarlos en los medios no te dan bolilla [... $]^{26}$. (Integrantes de la asamblea, comunicación personal)

También se dedica un tiempo a discutir las limitaciones de esos espacios: "Por ahí el periodista se engancha con un tema que no es lo central, como el cambio del nombre de la avenida y no me deja hablar, me pregunta sobre eso y dale que dale, cuando lo importante es el área de protección histórica” (integrantes de la asamblea, comunicación personal).

El comportamiento de quienes visitan y comentan los contenidos de la página es, asimismo, motivo de análisis:

Si son textos muy extensos no se leen [...] La primera foto tiene muchos “me gusta” y la última, ninguno [...] Hay una sección que está pegando muy bien [...] Tuvimos muy buenos resultados, con un efecto multiplicador [...] Sumamos más de mil amigos en un mes. [...] Nosotros intentamos que [la página de Facebook] no tenga un sesgo partidario, pero en los comentarios hay temas que se politizan, como en las fotos que muestran el abandono del policlínico ferroviario. (Integrantes de la asamblea, comunicaciones personales)

organizaciones o personas que deseen hacer un uso profesional o comercial de la información que publican. En lugar de "amigos" tienen fans (personas a las que les gusta la página). Desde allí también pueden compartir contenidos pero, a diferencia de lo que ocurre en los perfiles, no es posible hacer comentarios sobre estos. 
Como podemos observar, los usos de medios de comunicación, y en particular de las redes sociales en Internet, constituyen un aspecto central de las estrategias de la asamblea para posicionarse en la negociación con el estado municipal, en el contexto de un proceso sumamente dinámico en el que se van actualizando y reconfigurando las tensiones entre los actores involucrados. También en ese proceso, la asamblea se ha ido posicionando no solo como guardiana y constructora de una cierta memoria colectiva, sino de una utopía urbana, a partir de la voluntad de incidir en los rumbos de la ciudad que está por venir. Esto se expresa en la interpelación a (ciertas) generaciones futuras "que reivindicarán otras figuras y luchas” (integrante de la asamblea, comunicación personal).

\section{El barrio "de todos" y las casas de sus dueños: activación patrimonial de la identidad ferroviaria local}

La noción de lo público dista mucho de tener una significación unívoca. En tanto se vincula de manera directa con diferentes concepciones de sociedad, su propia definición es objeto de lucha. Como ha señalado Nora Rabotnikof:

[...] su utilización en el contexto de vocabularios políticos diferentes construye o identifica problemas también diferentes, evaluaciones y cursos de acción dispares. Se lo utiliza para adjetivar un "espacio", "una esfera”, se lo sustantiva (a veces sustancializa), se lo usa normativa o descriptivamente, y no siempre se tiene en cuenta que el trazado de los límites entre lo público y lo privado se modifica históricamente y que el conflicto por la definición de esos límites ha formado y forma parte de maneras específicas de concebir la vida política. $(1993,75)$

Una historización del concepto de lo público permite rastrear su surgimiento en la Grecia antigua, con categorías luego transmitidas al derecho romano, en cuya base se halla la distinción entre dos esferas: la doméstica, ligada a la resolución de necesidades básicas (oikos, lo económico, vinculado al hogar, la familia, la supervivencia y el espacio de la casa, asociado a intereses individuales o particulares de cada núcleo primario) y la esfera pública, un ámbito de la ciudadanía libre para el tratamiento debatido de los asuntos comunes. A partir de esta distinción básica, las diversas concepciones de lo público se han organizado en 
torno a tres ejes principales: el interés común, por oposición al interés individual; lo visible y manifiesto, expuesto a una opinión pública (lo público como publicidad, en sentido habermasiano); y lo abierto y accesible, en tanto espacio público.

Oposición históricamente producida, la diferenciación entre lo público y lo privado ha de ser considerada en sus manifestaciones concretas, a fin de permitir una problematización de las transformaciones contemporáneas en las vinculaciones entre estado y sociedad civil en la creación de lo público. En ese sentido, volviendo al caso en el que nos centramos para este artículo, cabe destacar que la construcción del barrio como patrimonio escenifica un conjunto de tensiones entre lo que se considera de interés colectivo, y por lo tanto bien superior, y la propiedad privada, que de hecho detentan los vecinos del barrio sobre las viviendas que se pretenden incluir dentro del área de protección histórica.

La lucha por la declaración de un área de protección histórica pone en juego un conjunto de apreciaciones y valoraciones respecto a lo que se consideran los intereses públicos y privados, por cuanto busca establecer jerarquías entre ellos. Se plantea así una tensión entre propiedad privada e interés público: “ya sé, estamos en una democracia capitalista. Si viviéramos en otro sistema, yo creo que el municipio ya lo hubiera expropiado" (integrante de la asamblea, comunicación personal).

En ese sentido, las acciones de la asamblea se posicionan en una verdadera lucha simbólica - propiamente política - por la imposición de la visión legítima sobre ese interés “común”: "La política es el lugar por excelencia de la eficacia simbólica, acción que se ejerce por signos capaces de producir cosas sociales, y en particular grupos” (Bourdieu 1990, 307). Dentro de esa lucha, la apelación al valor patrimonial de la historia y las construcciones del barrio aparece como un recurso importante en la contestación al interés "puramente económico” atribuido a la "especulación inmobiliaria”. Por un lado, el patrimonio contiene valores que se presentan como inconmensurables respecto de la "mera" rentabilidad: la identidad, la historia, la pertenencia, el arraigo, el afecto. Por otro lado, el patrimonio también constituye un potente recurso de generación de valor, ya no solo simbólico sino también económico, inmobiliario e incluso turístico. En la negociación con aquellos a quienes hay que “convencer” de la conveniencia de declarar el área de protección histórica, los asambleístas invocan los beneficios económicos que traería aparejados la medida, con el aumento del valor de las viviendas que se encuentren localizadas dentro de un área urbana con características singulares, o con la implementación de circuitos “turístico-culturales” que permitirían explotar el valor escenográfico del barrio. 
Cabe destacar que patrimonio es una categoría social en uso en el contexto al que estamos haciendo referencia, de manera que se nos impone la doble tarea de indagar en los supuestos que se actualizan en los discursos y prácticas "patrimoniales” de la asamblea, así como de situar su conceptualización, en términos analíticos, en el marco de la bibliografía específica. En este último sentido, es necesario tener en cuenta que el concepto de patrimonio ha sido objeto de numerosas redefiniciones y debates teóricos.

El patrimonio es una construcción social que involucra diferentes grados de conflicto en torno a la delimitación del repertorio patrimonial en juego. No se trata de "un conjunto de bienes estables y neutros, con valores y sentidos fijados de una vez para siempre, sino [de] un proceso social que [...] se acumula, se renueva, produce rendimientos, y es apropiado en forma desigual por diversos sectores” (García Canclini 2005, 94-95).

De acuerdo con Llorenç Prats (2005), los procesos de patrimonialización obedecen a dos construcciones sociales complementarias y sucesivas. La primera consiste en la sacralización de la externalidad cultural. Se trata de un mecanismo mediante el cual se define un ideal cultural del mundo y de la existencia, y todo aquello que no cabe en él o lo contradice pasa a formar parte de un "más allá". La redefinición de esta externalidad como sobrenaturalidad permite reintegrarla jerárquicamente en la experiencia cultural bajo la forma de religión, magia u otros sistemas de representación. En la perspectiva de este autor, el patrimonio es un sistema de representación que se basa también en esa externalidad cultural. Las metonimias, las reliquias que lo constituyen, son objetos, lugares o manifestaciones procedentes de la naturaleza virgen o indómita, por oposición al espacio domesticado por la cultura; del pasado, como tiempo fuera del tiempo, por oposición, no al tiempo presente, sino al tiempo percibido como presente; o de la “genialidad”, normalmente creativa pero también destructiva, como expresión de la excepcionalidad, de la superación y, en algún sentido, de los límites de la condición humana culturalmente establecidos. Este sistema de representación aparece con el desarrollo del capitalismo y la revolución industrial, y se apoya en su creciente separación de la naturaleza, del pasado y la valoración del individualismo y la singularidad en una sociedad adocenada, pero que, sin embargo, depende del ingenio.

Prats formula un conjunto de interrogantes que resultan significativos para pensar la persistencia y diversificación de los procesos de patrimonialización en la modernidad tardía:

¿Por qué el patrimonio? ¿Por qué se recurre a los procesos de patrimonialización, con mayor intensidad que a otros sistemas de símbolos, 
como una especie de religión laica, para legitimar identidades, empresas, discursos? ¿Por qué lo que había sido despreciado o explotado como baldío, viejo o excéntrico es ahora preservado y celebrado en templos ad hoc? ¿Por qué esta percepción del patrimonio se difunde progresivamente hasta los rincones más recónditos de la sociedad capitalista occidental y sus zonas de influencia? Pero, sobre todo, ¿por qué se perpetúa con tal fuerza hasta nuestros días? $(2005,19)$

A partir de estos principios compartidos, se produce una segunda construcción social en el proceso de patrimonialización: la activación patrimonial. Esta involucra la selección de elementos integrantes de la activación, la ordenación de estos elementos y la interpretación o restricción de la polisemia de cada uno. A nuestro entender, las estrategias de activación patrimonial constituyen un aspecto fundamental en la búsqueda de legitimación de los reclamos de la asamblea. El proyecto de un área de protección histórica demanda el reconocimiento jurídico de un conjunto de bienes simbólicos como "patrimonio", bienes de un determinado estatus que ameritarían su resguardo. Asimismo, se pone en juego una actualización selectiva del pasado (Williams 1980) y la invocación de una ciudad deseada a futuro, al tiempo que los asambleístas se posicionan en la lucha por los “problemas urbanos” relevantes ${ }^{27}$ que requieren intervención estatal.

\section{Conclusiones}

Hemos realizado en estas páginas algunas reflexiones con base en el acercamiento a un caso, en el contexto de una ciudad media de la provincia de Buenos Aires, Argentina, en el que se ponen en juego una serie de usos y sentidos en torno a lo público, a partir de un proceso de activación patrimonial impulsado por una asamblea vecinal.

La demanda de un área de protección histórica permite desvelar la compleja y dinámica trama de relaciones que se configuran a diario, en el contexto urbano-barrial, entre los procesos histórico-estructurales de producción de lo

27 Una integrante de la asamblea, al referirse a una acción de protesta por el envenenamiento de cinco árboles de tilo en una de las avenidas emblemáticas del barrio, lo expresaba en los siguientes términos: "mucha gente dirá, 'con los problemas que hay, ¿se van a preocupar por un árbol?'. Pero lo cierto es que alguien lo tiene que hacer, porque es algo que tiene que ver con la identidad, no solo del barrio, sino de todos los ciudadanos" (integrante de la asamblea, comunicación personal). 
urbano y la construcción de imaginarios identitarios. Dichos imaginarios mediatizan los modos en que esos procesos son vividos, sufridos, alentados y proyectados; por ejemplo, este es el caso de las acciones de la asamblea que buscan concretar la ciudad deseada - una donde quepa el resguardo de esa vida obrera ferroviaria añorada-. Estas dinámicas macroestructurales constituyen las condiciones de posibilidad de perfiles productivos, mundos del trabajo y del desempleo, que se articulan dialécticamente con las identidades urbanas y barriales, la vida asociativa y la sociabilidad cotidiana. En su propuesta, los integrantes de la asamblea actualizan selectivamente elementos del pasado local -el palimpsesto urbano- y reivindican ciertas referencias identitarias en detrimento de otras, específicamente aquellas ligadas a la historia del movimiento obrero ferroviario en la ciudad.

En este sentido, recuperamos los aportes de Gravano (2013) respecto al eje axiológico de la identidad barrial, en tanto conjunto estructurado de valores presentes en la ideología sobre el barrio. El barrio entendido como espacio se subordina al barrio entendido como tiempo-éthos, con capacidad para construir ideológicamente una identidad.

En el contexto de un proceso sumamente dinámico en el que se van actualizando y reconfigurando las tensiones entre los actores involucrados, el recurso a los medios de comunicación y, en particular, a las redes sociales en Internet adquiere un lugar central en las estrategias de la asamblea para posicionarse en la negociación con el estado municipal. También resulta indispensable en el posicionamiento de la asamblea respecto a otros actores, como en el caso ya mencionado del monumento a Juan Domingo Perón en la plaza de la estación, cuya edificación fue propuesta por un sector del Partido Justicialista local.

En torno a la demanda de protección patrimonial se articulan diferentes posiciones en tensión, entre las que podemos reconocer, por un lado, aquellas de la "especulación inmobiliaria” y la búsqueda de la "mera rentabilidad", frente a lo cual se apela a una argumentación en términos de valor de cambio y estrategias de distinción, con la valorización de las propiedades y la posibilidad de desarrollar proyectos turísticos. Por otro lado, podemos reconocer la posición de un estado que, en sus diferentes niveles - sobre todo municipal y provincial - es interpelado en su rol regulador. La formulación de políticas públicas aparece entonces en relación con tareas de diagnóstico y reconocimiento de problemas a resolver, así como con el establecimiento de prioridades entre esos problemas. Mencionábamos más arriba que en algunas respuestas de actores del municipio aparece la apelación al Plan de Desarrollo Territorial, en la que se argumenta — también en nombre del "interés colectivo"- que la zona de la estación debe densificarse 
ante la demanda habitacional de la ciudad. ¿Densificar o proteger la identidad? ¿De qué modo conciliar estos intereses colectivos confrontados?

A partir del caso abordado, nos preguntamos por los contenidos concretos que se les asignan a las categorías de interés colectivo y bien común, como una posible puerta de entrada para pensar la condición constitutivamente conflictiva de la producción de lo urbano. Este análisis se hace desde una indagación sobre los procesos de gestión urbana en sentido amplio, como modos de hacer ciudad, y sobre los usos y sentidos de lo público, en tanto que instancias que pueden devenir democratizadoras o fragmentadoras del acceso al sistema de sistemas de servicios urbanos.

\section{Referencias}

Achilli, Elena. 2005. Investigar en antropología social. Los desafíos de transmitir un oficio. Rosario: Laborde.

Ansart, Pierre. 1989. Ideologías, conflictos y poder. México D. F.: Premia.

Asamblea del barrio de La Estación. (2013) "El barrio de la estación como área de protección histórica”. Mimeo. Consultado el $1 .^{\circ}$ de marzo de 2015. www.barriolaestaciontandil.blogspot. com.ar/p/elproyecto.html.

Auyero, Javier. 2002. "Los cambios en el repertorio de la protesta social en Argentina”. Desarrollo Económico. Revista de Ciencias Sociales 42 (166): 187-210.

Barandiarán, Luciano y Ana Silva. 2014. "Cine, teatro y política en la sociabilidad barrial: la memoria en torno a las 'veladas socialistas' en el barrio de La Estación (1930-1946)”. Ponencia presentada en las II Jornadas Internacionales y V Nacionales de Historia, Arte y Política. Tandil, Argentina, septiembre.

"El barrio de La Estación busca preservar su identidad arquitectónica, histórica y cultural”. 2014. Nueva Era, 16 de agosto. Consultado el $1 .^{\circ}$ de marzo de 2015. http://www.nuevaeranet.com.ar.

Boggi, Silvia. 2009. "Identidades urbanas locales en Facebook. Reflexiones acerca del trabajo etnográfico en el ciberespacio”. Ponencia presentada en las II Jornadas de Antropología Social del Centro Bonaerense. Olavarría, Argentina, septiembre.

Boggi, Silvia y Nora Galván. 2008. “Ni chicha ni limonada. Apuntes reflexivos acerca de las nociones de ciudad media y ciudad intermedia”. Ponencia presentada en el IX Congreso Argentino de Antropología Social. Misiones, Argentina, agosto.

Bourdieu, Pierre. 1990. Sociología y cultura. México D. F.: Grijalbo.

—. 2003. Intelectuales, política y poder. Buenos Aires: Eudeba.

Carvalho da Rocha, Ana Luiza y Cornelia Eckert. 2013. Etnografia da duração. Porto Alegre: Marcavisual.

Castoriadis, Cornelius. (1989) 2003. La institución imaginaria de la sociedad. Vol. 2 de El imaginario socialy la institución. Barcelona: Tusquets. 
Colombo, Eduardo. 1989. El imaginario social. Montevideo: Nordan.

"Entrevista a integrante de la asamblea". 2012. Política Tandil, $1 .^{\circ}$ de noviembre. www.politicatandil.com.

Faccin, Danielle y María Zanini. 2013. "Percepções acerca do morar em um lugar de memória: o caso da 'Mancha Ferroviária’ de Santa Maria (1996-2013)”. Ponencia presentada en el $37 .^{\circ}$ Encuentro de la Associação Nacional de Pós-Graduação e Pesquisa em Ciências Sociais. Águas de Lindóia, Brasil, septiembre.

García Canclini, Néstor. 2005. Imaginarios urbanos. Buenos Aires: Universidad de Buenos Aires.

Girado, Agustina. 2012. “'El verde se está secando': conflicto socioambiental en el partido de Tandil en torno a la gestión, utilización y ocupación del sistema serrano durante el periodo 2006-2010". Tesis de licenciatura, Facultad de Ciencias Sociales, Unicen.

Grassi, Estela. 2004. Políticas y problemas sociales en la sociedad neoliberal. La otra década infame (II). Buenos Aires: Espacio Editorial.

Gravano, Ariel, comp. 2005. Imaginarios sociales de la ciudad media. Emblemas, fragmentaciones y otredades urbanas. Estudios de antropología urbana. Tandil: REUN.

—. 2011. "Imaginarios barriales y gestión social: trayectorias y proyecciones a dos orillas”. En Anuario de Antropología Social y Cultural en Uruguay 2010-2011, 51-65. Montevideo: Nordan.

-. 2013. Antropología de lo urbano. Tandil: REUN.

Halbwachs, Maurice. (1950) 2004. La memoria colectiva. Zaragoza: Prensas Universitarias.

Hammersley, Martyn y Paul Atkinson. 1983. Ethnography Principies in Practice. Londres: Tavistock.
Honorable Concejo Deliberante de Tandil. s. f. Banca 21. Consultado el 15 de junio de 2015. http://www.hcdtandil.gob. ar/banca21.php.

\section{Instituto Nacional de Estadísticas y} Censos (Indec). 2010. Censo 2010. http:// www.censo2010.indec.gov.ar/CuadrosDefinitivos/P2-D_6_791.pdf.

López, Mario Justo y Jorge Waddell. 2007. Nueva historia del ferrocarril en la Argentina: 150 años de política ferroviaria. Buenos Aires: Lumiere.

Lynch, Kevin. 1966. La imagen de la ciudad. Buenos Aires: Infinito.

Martínez, Juan Pablo. 2007. “1977-2006: el ciclo de las reformas traumáticas”. En Nueva historia del ferrocarril en la Argentina: 150 años de política ferroviaria, compilado por Mario Justo López y Jorge Waddell, 209-286. Buenos Aires: Lumiere.

Mengascini, Hugo. 2011. Huelgas y conflictos ferroviarios. Los trabajadores de Tandil en la segunda mitad del siglo XX. Rosario: Prohistoria.

Migueltorena, Alejandro y Diana Lan. 2013. "Racionalidades y contrarracionalidades, a partir de la vivienda, en la producción del espacio urbano de Tandil, Argentina”. Cuadernos de Geografía. Revista Colombiana de Geografía 22 (1): 109-125.

Nario, Hugo. 1996. Tandil, historia abierta. Tandil: Del Manantial.

Portelli, Alessandro. 1989. "Historia y memoria: la muerte de Luigi Trastulli”. Historia y Fuente Oral 1: 5-32.

Prats, Llorenç. 2005. "Concepto y gestión del patrimonio local”. Cuadernos de Antropología Social 21: 17-35.

Proincomsci. 2013. Imaginarios del sistema de servicios urbanos y procesos de gestión con participación en ciudades de rango 
medio. Consultado el 20 de mayo de 2015. http://www.soc.unicen.edu.ar/proin comsci/index.php/proyectos/proyectosvigentes.

Rabotnikof, Nora. 1993. "Lo público y sus problemas. Nota para una reconsideración”. Revista Internacional de Filosofía Política 2: 75-98.

Raggio, Alejandro. 2012. "Identidades en movimiento: el caso del barrio Peñarol”. Tesis de maestría, Facultad de Humanidades y Ciencias de la Educación, Universidad de la República de Uruguay.

Rapoport, Mario. 2006. Historia económica, política y social de la Argentina (18802003). Buenos Aires: Ariel.

Rockwell, Elsie. 1987. "Reflexiones sobre el proceso etnográfico (1982-1985)”. En La práctica docente y sus contextos institucionaly social, vol. 2, coordinado por Elsie Rockwell y Justa Ezpeleta, 2-57. México D. F.: DIE.

Sader, Emir y Pablo Gentili, comps. 2003. La trama del neoliberalismo. Mercado, crisis y exclusión social. Buenos Aires: Clacso.

Silva, Ana. 2011. Imágenes e imaginarios urbanos en la "ciudad de las sierras". Iluminuras 11 (2011): 1-22.
—. 2013. "Sentidos y valores del 'trabajo' en la configuración de identidades urbanas y legitimación de demandas al estado". Kula Antropólogos del Atlántico Sur 7: 38-52.

Silva, Ana y Ariel Gravano. 2013. "Reinventando espacialidades: gobierno electrónico e imaginarios urbanos en ciudades de rango medio”. Ponencia presentada en la X Reunión de Antropología del Mercosur. Córdoba, Argentina, julio.

Silva, Armando. 1992. Imaginarios urbanos. Bogotá y Sao Paulo: cultura y comunicación urbana en América Latina. Bogotá: Tercer Mundo.

Tartarini, Daniel. 2007. "Arquitectura ferroviaria en la provincia de Buenos Aires”. En Nueva historia del ferrocarril en la Argentina: 150 años de política ferroviaria, compilado por Mario Justo López y Jorge Waddell, 455-484. Buenos Aires: Lumiere.

Tilly, Charles. 2000. La desigualdad persistente. Buenos Aires: Manantial.

Williams, Raymond. 1980. Marxismo y literatura. Barcelona: Península. 